\title{
Description of the larva of Protanypus sp. A (Diptera, Chironomidae) from the Italian Alps
}

\author{
B. Rossaro, ${ }^{1}$ A. Boggero,, ${ }^{2}$ F. Buzzi, ${ }^{3}$ C. Agostinelli, ${ }^{3}$ F. Nastasi ${ }^{3}$ \\ 1Dipartimento di Protezione dei Sistemi Agroalimentare e Urbano e Valorizzazione delle Biodiversità \\ (Di.P.S.A.), Università degli Studi di Milano; ${ }^{2}$ CNR-ISE Istituto per lo Studio degli Ecosistemi, \\ Verbania Pallanza; ${ }^{3}$ Arpa Lombardia, Lecco, Italy
}

\begin{abstract}
We describe the larva of Protanypus sp. A from the Italian Alps. All the larval characteristics fit the diagnosis of the genus, but it is impossible to assign the specimens examined to one of the known species. The low number of labral scales (12-14) and the serrated median lamellae of the medioventral appendix of the prementum exclude the identity of the species with $P$. morio or with the East Palaearctic $P$. pseudomorio. The antennal ratio (2.3) excludes the identity with $P$. caudatus or $P$. forcipatus, which are the other two Protanypus species known from the Alpine region. In Sæther's key (1975) the larva fits with the Nearctic $P$. ramosus, but identification of the species needs to be supported by pupal and adult material. In the Southern Alps, the genus is restricted to cold lakes at high altitude and is confirmed as an indicator of oligotrophic lakes.
\end{abstract}

\section{Introduction}

Larval material belonging to the genus Protanypus was recently col-

Correspondence: Bruno Rossaro, Dipartimento di Protezione dei Sistemi Agroalimentare e Urbano e Valorizzazione delle Biodiversità (Di.P.S.A.), Università degli Studi di Milano, Italy. E-mail: bruno.rossaro @unimi.it

Key words: taxonomy, Chironomidae, ecology.

Acknowledgements: the authors are grateful to Arpa Lombardia and CNR-ISE for collecting the material, to the Università degli Studi, Milan (DeFND) and to the CNR-ISE allowing us to examine the samples in their collections. Our thanks also go to the reviewers for their invaluable suggestions.

Received for publication: 9 March 2012

Revision received: 13 April 2012

Accepted for publication: 13 April 2012

(C) Copyright B. Rossaro et al., 2012

Licensee PAGEPress, Italy

Journal of Entomological and Acarological Research 2012; 44:e6 doi:10.4081/jear.2012.e6

This article is distributed under the terms of the Creative Commons Attribution Noncommercial License (by-nc 3.0) which permits any noncommercial use, distribution, and reproduction in any medium, provided the original author(s) and source are credited. lected in the Southern Alps. The genus is considered to be an indicator of oligotrophic conditions in lakes (Sæther, 1979). There are few records of the genus on the southern side of the Alps and the material collected was never described. The genus is Holarctic in distribution with three species known to occur in Europe, P. caudatus Edwards, 1924, P. forcipatus (Egger, 1864) and P. morio (Zetterstedt, 1838), two species from East Palearctic, P. pseudomorio Makarchenko, 1982, also captured in Alaska (Sæther and Willassen, 1985), and P. tshereshnevi Makarchenko, 1982, three species from North America, P. ramosus Sæther, 1975, P. hamiltoni Sæther, 1975 and P. sætheri Wiederholm, 1975. Two other species were described as larvae (Sæther, 1975; Ashe and 0'Connor, 2009). The genus is restricted to cold oligotrophic lakes and is considered an indicator of oligotrophy (Sæther, 1979). The larva was described by Sæther (1975), Doughman (1983), Wiederholm (1983) and Makarchenko (2006).

\section{Materials and methods}

Larvae were fixed in $70 \%$ ethanol, body parts were dehydrated in acetic acid, butanol, phenol 3: xylene 1 (Wirth and Marston, 1968) and slide-mounted in Canada balsam. The larval head capsule was dissected as described by Wiederholm (1983). Terminology and abbreviations used in the description follow Sæther $(1976,1980)$. Measurements are according to Sæther (1976) and are given in $\mu \mathrm{m}$, unless otherwise specified.

\section{Results}

\section{Diagnosis}

The larvae do not exceed $10 \mathrm{~mm}$ in length. The postoccipital margin has only a small ventrolateral, posteriorly directed projection on each side (Figure 1 poc). Antennal ratio is over 2.0, there are 12-14 labral scales (Figure 1 lab), the median tooth of mentum is very large (Figure $1 \mathrm{mnt}, \mathrm{prh}$ ), and the median lamellae of medio-ventral appendix of prementum serrated (Figure $1 \mathrm{prh}$ ). Procerci are approximately $100 \mu \mathrm{m}$ long.

\section{Description}

The description is based on 2 larvae at the $4^{\text {th }}$ stage and 3 larvae at the $3^{\text {rd }}$ stage, collected in Lake Palù (Lombardy, Italy). These are medium-sized, large larva in the $4^{\text {th }}$ stage, approximately $10 \mathrm{~mm}$ long. The head capsule is covered with numerous small setae and there is a small ventrolateral projection on its occipital margin on each side. The antenna (Figure 1 ant, Figure 2 ant, Figure 3, Figure 


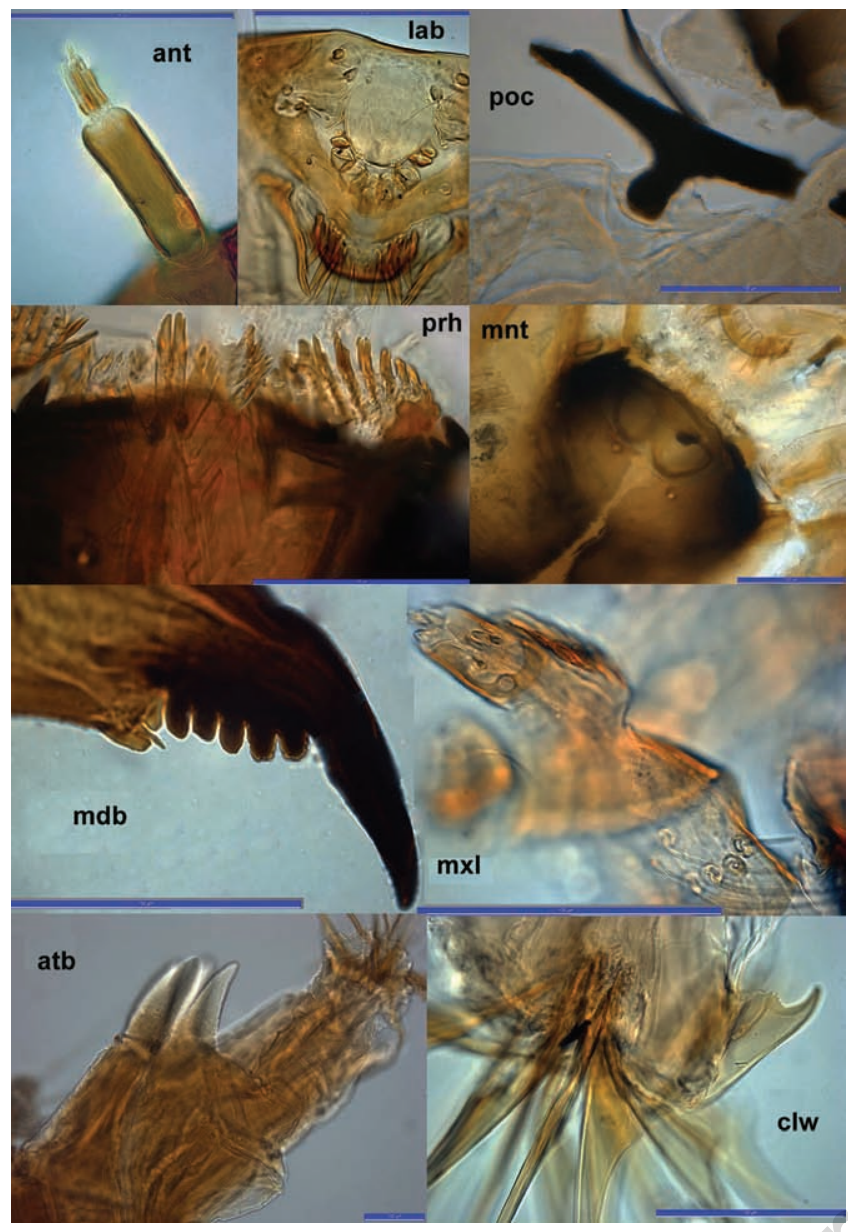

Figure 1. The larva of Protanypus sp. A. Ant, antenna; lab, labrum; poc, prolongation of occipital margin of head capsule; mnt, mentum; prh, prementum and hypopharinx; mdb, mandible; mxl, maxilla; atb, anal tubules; clw, claws of posterior prolegs. Blue bar: $100 \mu \mathrm{m}$.

4) has 4 segments. Antennal segments are 78.2, 21.7, 2.7, $6.5 \mu \mathrm{m}$ long. Antennal ratio (AR) is 2.26: $1^{\text {st }}$ segment is very long, $2^{\text {nd }}$ is shorter, $3^{\text {rd }}$ segment is very short, $4^{\text {th }}$ segment is much longer than the $3^{\text {rd }}$. The antennal blade is $26 \mu \mathrm{m}$ long, accessory blade $23 \mu \mathrm{m}$, style 5.6 $\mu \mathrm{m}$, Lauterborn organ $8.9 \mu \mathrm{m}$. The ring organ near the base of antenna is only $13 \mu \mathrm{m}$ from the base and approximately $62 \mu \mathrm{m}$ from the distal margin of the first antennal segment. All S setae of the labrum (Figure 1 lab, Figure 5, Figure 6) are short and simple. There are approximately 12-14 labral scales. These are broad, leaf-like, circular, apically serrated, overlapping, and disposed in a semicircular row. There are no lateral chaetae, pecten epipharyngis consists of 3 large scales, pointed at the apex, continuous with chaetulae laterals. There is a narrow premandible with a well-developed, but very slender inner tooth. The other 2 teeth are very small and difficult to see. The mandible (Figure $1 \mathrm{mdb}$, Figure $2 \mathrm{mdb}$ ) has 5 inner teeth and a very long slender apical tooth. The seta subdentalis is pointed and narrow. There are no seta interna. The mentum (Figure $1 \mathrm{mnt}$, prh, Figure 2 mnt, MApp, PH) has a very large transparent median tooth. The width of the whole mentum is $142 \mu \mathrm{m}$. Two to three lateral teeth are restricted to the extreme lateral region (Figure $2 \mathrm{PH}$ ). Ventromental plates are present but not developed (Figure $2 \mathrm{PH}$ ). The supporting endoskeleton is $190 \mu \mathrm{m}$ wide. The medio-ventral appendix M (Figure 2 MApp) is $12.6 \mu \mathrm{m}$ at its narrowest point, $38.7 \mu \mathrm{m}$ at its base, with median lamellae serrated at its apex. The ratio of supporting

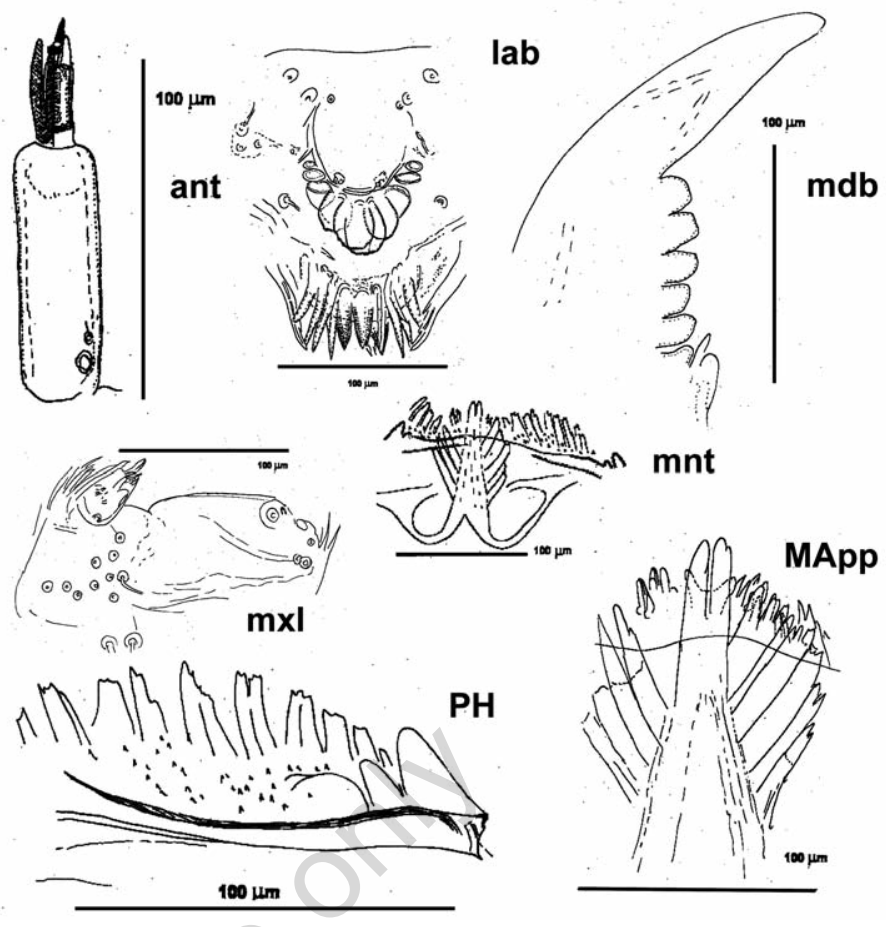

Figure 2. The larva of Protanypus sp. A. Ant, antenna; lab, labrum; mdb, mandible; mxl, maxilla; mnt, mentum; MApp, median appendage of prementum; $\mathrm{PH}$, margin of mentum and pecten hypopharyngis.

endoskeleton to median tooth of mentum is approximately 1.4. The ratio of the medio-ventral appendix of prementum is 3.1 at its base to its minimum width. The pecten hypopharyngis has well-developed scales (Figure 1 prh, Figure $2 \mathrm{PH}$ ). Maxilla (Figure $1 \mathrm{mxl}$, Figure 2 $\mathrm{mxl}$ ): palp is longer than it is wide, and there are numerous setae maxillaris. The anal tubules of the body are triangular (Figure $1 \mathrm{atb}$ ) with long narrow claws on the anterior and posterior parapods. There are few claws with small denticles (Figure $1 \mathrm{clw}$ ) on the posterior parapods. The procerci are approximately $100 \mu \mathrm{m}$ long with 5 setae at the apex. The larvae described here were collected in Lake Palù, Sondrio, Lombardy, Italy (lat. $46^{\circ} 17$ ’ 59 ” 5127957.30 WGS/84 UTM 32N; long. $9^{\circ} 52^{\prime} 06^{\prime}$ "567045.75 WGS/84 UTM 32N) on 2 August 2011 (depth $6 \mathrm{~m}$, water temperature $13^{\circ} \mathrm{C}$, oxygen saturation 90\%) and on 2 September 2011 at the same station. Previous records of the genus from the southern side of the Alps are from the lakes Laiozza (19/9/1991) and Zota (19/9/1991) in the Lavizzara Valley, river basin of Maggia, one of the tributaries of the River Ticino (Switzerland), and from the lakes Paione Medio and Superiore (13/9/2000) in the Ossola Valley, river basin of the Bognanco (tributary of the River Toce), Verbania, Piedmont, Italy. The genus is also known from the northern side of the Alps from Lake Constance (Reiss, 1968), and from southern Germany and the Austrian lakes (Faaker See, 11/6/2008 and Vorderlang See, 25/6/2008) (Free et al., 2009).

\section{Discussion}

The species will be keyed to the Nearctic $P$. ramosus using the key of Sæther (1975). The previous reports of the genus Protanypus in Italy can be confirmed in the generic diagnosis, but the citation of $P$. caudatus (Boorman et al., 1995) cannot be confirmed on the basis of larval material; the AR is over 2.0, and this value is only reported for 


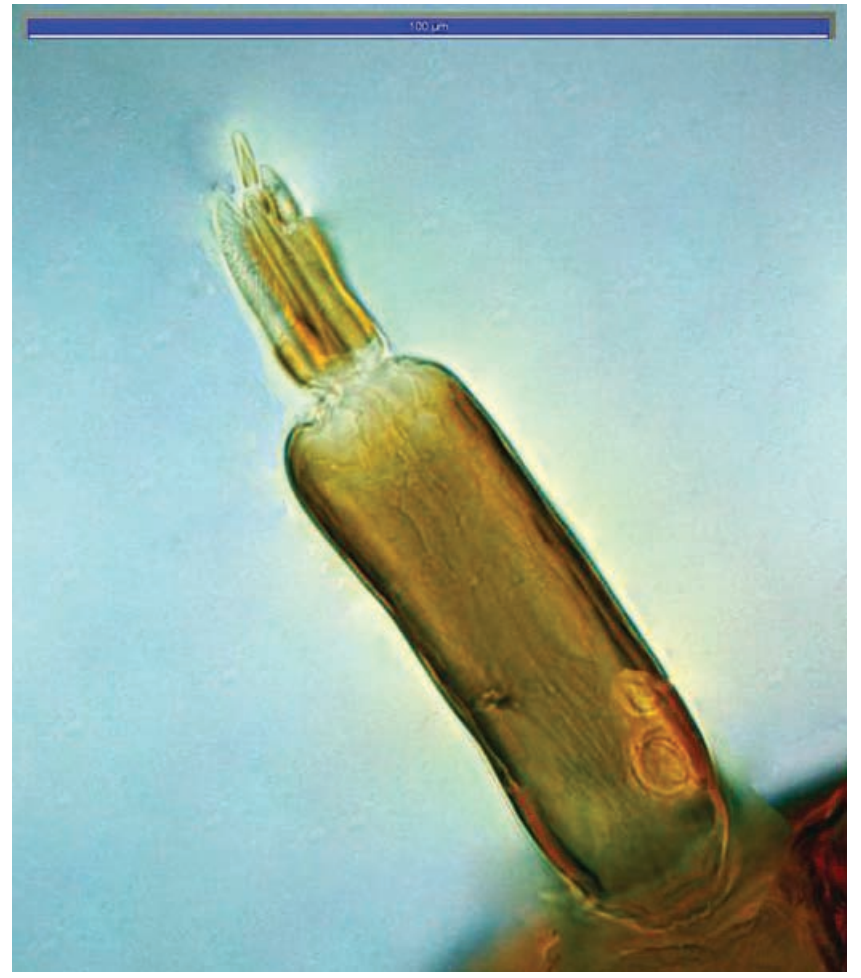

Figure 3. Antenna: the four antennal segments with antennal blade, accessory blade and ring organ.

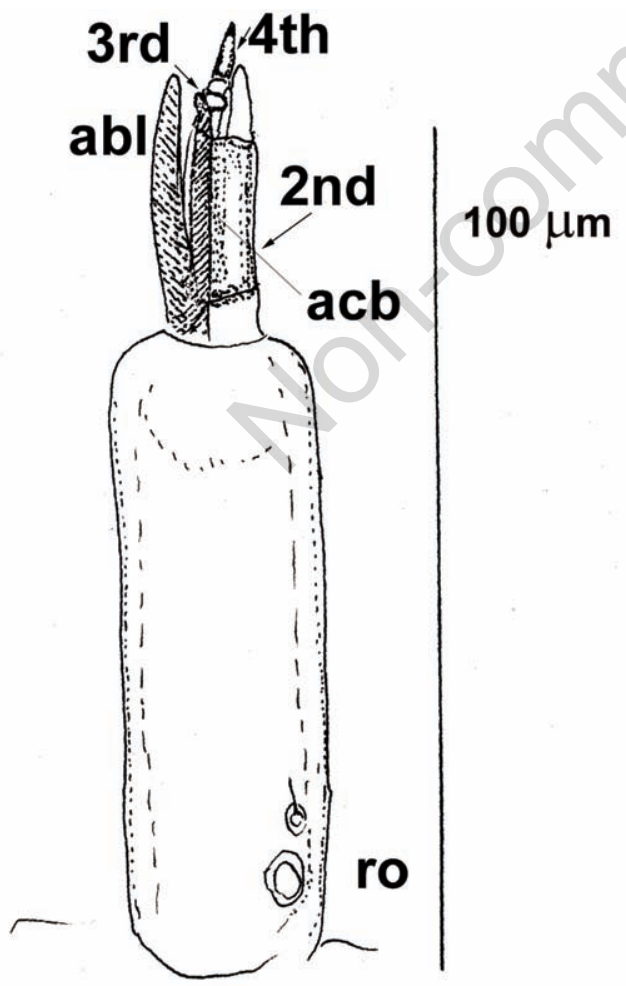

Figure 4. Antenna: abl, antennal blade; acb, accessory blade; ro, ring organ; $2^{\text {nd }}, 3^{\text {rd }}, 4^{\text {th }}$, second, third and fourth antennal segments.
Figure 6. Labrum: lb, labral scales; prm, premandibles; eph, pecten epipharyngis.

Figure 5. Labrum: labral scales, epipharynx, premandibles.

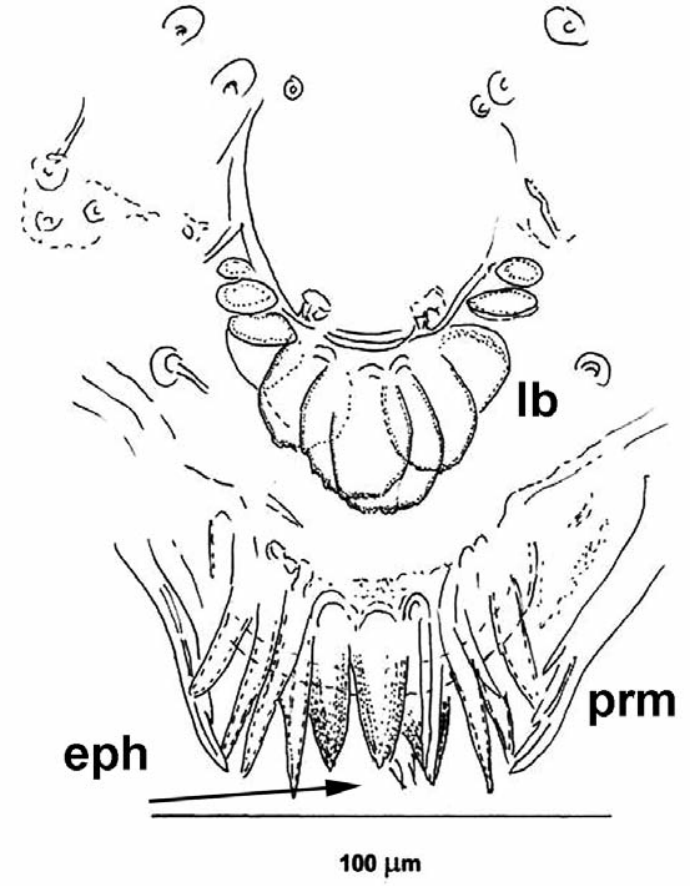


Nearctic material. The genus is well described and documented in the adult and in the pupal stages (Brundin, 1952; Wiederholm, 1975; Makarchenko, 1982; Sæther and Willassen, 1985). A short description of the genus in the larval stage has been given by Wiederholm (1983). Different species of the genus have been described by Zavrel (1926), Hirvenoja (1973), Sæther (1975), Doughman (1983) and Makarchenko (2006). Unfortunately, Makarchenko's description of $P$. caudatus (2006) does not agree with the description of Sæther (1975) because the first author described the species as having 16-20 labral scales, while Sæther reports that the species has no more than 12 labral scales. Also other characteristics, such as the premandible, do not help identify the species; Protanypus sp. A has a premandible with 3 teeth, like the $P$. caudatus (Makarchenko, 2006). P. pseudomorio has a premandible with 5 teeth. The ratio between the medioventral appendix of the prementum, the minimum width at its base and between the supporting endoskeleton of the appendix, and the median tooth width of the mentum were used as characteristics to distinguish between species (Sæther, 1975). However, these criteria are difficult to apply, and it must be emphasized that many morphometric characteristics change with larval size.

\section{Conclusions}

The larvae of Protanypus can easily be identified to genus but the species determination within the genus according to morphometric measurements is still highly problematic since these depend on larval size. In this case, unless pupae and adults are examined the species should not be named. Attempts are now being made to identify larvae using molecular markers (Willassen, 2011). Preliminary results require confirmation because of the modest levels of phylogenetic signal obtained with low credibility of some nodes. From an ecological point of view, all samples of the genus captured come from high altitude oligotrophic lakes, over $1900 \mathrm{~m}$. The larvae are free living and predatory. In the Alps, they have been reported to be limited to the profundal zone, but our samples were taken at a depth of $6 \mathrm{~m}$.

\section{References}

ASHE P., O'CONNOR J.P., 2009 - A World catalogue of Chironomidae (Diptera) Part 1. Buchonomyiinae, Chilenomyiinae, Pononominae, Aphroteniinae, Tanypodinae, Usambaromyiinae, Diamesinae, Prodiamesinae and Telmatogetoninae. The Irish Bio geographical Society in association with The National Museum of Ireland: $445 \mathrm{pp}$.

BOORMAN J., COLUZZI M., CONTINI C., FERRARESE U., RIVOSECCHI L., ROSSARO B., et al., 1995 - Diptera Culicomorpha (in MINELLI A., RUFFO S., LA POSTA S., (Eds.), Checklist delle specie della Fauna Italiana. Calderini, Bologna, Italy: 65:1-32.
BRUNDIN L., 1952 - Zur Kenntnis der Taxonomie and Metamorphose der Chironomidengattungen Protanypus Kieff., Prodiamesa Kieff. und Monodiamesa Kieff. Rep. Inst. Freshwater Res. Drottningholm 33: 39-53.

DOUGHMAN J.S., 1983 - A guide to the larvae of the Nearctic Diamesinae (Diptera, Chironomidae). The genera Boreoheptagyia, Protanypus, Diamesa and Pseudokiefferiella. U.S. Ecological Survey. - Water Research Investigation Rep. 83-4006: 1-58.

FREE G., SOLIMINI A., ROSSARO B., MARZIALI L., GIACCHINI R., PARACCHINI B., et al., 2009 - Modelling lake macroinvertebrate species in the shallow sublittoral: relative roles of habitat, lake morphology, aquatic chemistry and sediment composition. Hydrobiologia 633: 123-136.

HIRVENOJA M., 1973 - Revision der Gattung Cricotopus van der Wulp and ihrer Verwandten (Diptera, Chironomidae). - Ann. Zool. Fenn. 10: 1-363.

MAKARCHENKO E.A., 1982 - Khironomidy roda Protanypus Kieffer (Diptera, Chironomidae) dal'nego Vostoka SSSR, (in Biologiya presnovodnykh zhivotiykh dal'nego Vostoka.) Akad. Nauk SSSR: 125-144.

MAKARCHENKO, E.A,. 2006 - 34. Chironomidae. In: Key to the insects of Russian Far East. Vol. VI. Diptera and Siphonaptera Pt. 4: 204734.

REISS, F., 1968 - Ökologische und Systematische Untersuchungen an Chironomiden (Diptera) des Bodensees. - Arch. Hydrobiol. 64: 176-323.

SÆTHER 0. A., 1975 - Two new species of Protanypus Kieffer, with keys to Nearctic and Palaearctic species of the genus (Diptera: Chironomidae). - J. Fish. Res. Bd Can. 32: 367-388.

SÆTHER 0.A., 1976 - Revision of Hydrobaenus, Trissocladius, Zalutschia, Paratrissocladius, and some related genera (Diptera Chironomidae). - Bull. Fish. Res. Bd. Canada. 195: 1-287.

SÆTHER 0.A., 1979 - Chironomid communities as water quality indicators. - Holarctic Ecol. 2: 65-74.

SÆTHER 0. A., 1980 - Glossary of Chironomid morphology terminology (Diptera: Chironomidae). - Entomol. Scand. Suppl. 14: 1-51.

SÆTHER 0. A. and WILLASSEN E., 1985 - The first record of Protanypus pseudomorio Makarchenko (Diptera Chironomidae) from the Nearctic, with a Description of the Female and a revised Key to Males of the Genus. - Aquat. Insects 7: 141-148.

WIEDERHOLM T., 1975 - Description of Protanypus sætheri n.sp. from Alaska (Diptera: Chironomidae). - Entomol. Scand. 6: 224-228.

WIEDERHOLM T., 1983 - Chironomidae of the Holarctic region. Part I larvae. - Entomol. Scand. Suppl. 19: 1-457.

WILLASSEN E., 2011 - Phylogeny of Diamesinae inferred from mtDNA sequences. Abstract Volume. Eighteenth International Symposium on Chironomidae, Throndheim, Norway, 4-6 July 2011: 49 .

WIRTH W.W. and MARSTON N., 1968 - A method for mounting small insects on microscope slides in Canada Balsam. - Ann. Entomol. Soc. Am. 61: 783-784.

ZAVREL J., 1926 - Chironomiden aus Wigry-See. - Arch. Hydrobiol. Ichtyol. 1: 197-220. 